\title{
An empirical study of user acceptance of online social networks marketing
}

\author{
Olumayoma Mulero, Michael Adeyeye \\ Department of Information Technology, Cape Peninsula University of Technology, South Africa
}

\begin{abstract}
The explosion of Internet usage has drawn the attention of researchers towards online Social Networks Marketing (SNM). Research has shown that a number of the Internet users are distrustful and indecisive, when it comes to the use of social networks marketing system. Therefore, there is a need for researchers to identify some of the factors that determine users' acceptance of social networks marketing using Technology Acceptance Model (TAM). This study extended the Technology Acceptance Model theoretical framework to predict consumer acceptance of social networks marketing within Western Cape Province of South Africa. The research model was tested using data collected from 470 questionnaires and analysed using linear regression. The results showed that user intentions to use SNM are strongly and positively correlated with user acceptance of using SNM systems. Empirical results confirmed that perceived credibility and perceived usefulness are the strongest determinant in predicting user intentions to use SNM system.
\end{abstract}

KEYWORDS: Technology Acceptance Model, e-Commerce, Advertisement, Social Network Sites

CATEGORIES: H.1.1

\section{INTRODUCTION}

Online Social Network (OSN) is a new world of networking, where people can exchange ideas, experiences and contacts. Websites are commonly used as a medium for Online Social Networks (OSNs), and they provide significant potentials for business owners and consumers [1. Online Social Network Sites (SNSs) support both the maintenance and solidification of existing offline social relationship and facilitate the creation of new ones [2]. Primarily, OSNs provide benefit for the users by creating a medium to communicate and connect with friends, colleagues and family. Recently, online social networks have found application in e-Commerce, especially for advertisements and other business transactions 3 .

In addition, marketing is becoming more significant for consumers and organizations that are actively involved in all kind of e-Commerce activities. The use of social networks marketing not only helps to manage customer relationships, but also attracts employees and investors 4. Online Social Networks Marketing (OSNM) has overhauled the traditional forms of marketing in such a way that millions of prospective buyers can be reached globally within a minute. OSNM also allows small companies to market and advertise in a difficult market [5]. Many companies adopt OSNM because they found it faster and cheaper compared to traditional marketing. This outstanding potential

Email: Olumayoma Mulero mulero_mayowa@yahoo.com, Michael Adeyeye adeyeyem@cput.ac.za (compared with traditional marketing) has been exploited and explored by consumers and organizations in order to promote their businesses [6.

In South Africa, consumer attitudes to online marketing and shopping are hampered by the issue of privacy, security and confidentiality of online transactions. According to [5], a great number of South Africans agreed that providing credit card information to sellers is a major problem that dissuades them from online marketing and shopping. Another barrier to consumer adoption of Internet marketing and shopping in South Africa is the cost of Internet access. Telkom' 1 monopoly has made the service expensive for the public to afford.

With the vast growth in the use of social networks marketing around the globe, research carried out by Mulero and Adeyeye [6] on the use of social networks marketing by SMEs in South Africa showed that many SMEs in South Africa are still in a testing phase, compared to their counterparts in developed countries. This slow growth was as a result of some challenges, such as lack of awareness, privacy and confidentiality, lack of time and the cost of accessing the Internet. All these challenges have affected the growth and development of SNM in South Africa.

This study investigates factors that influence users acceptance of OSNM using Technology Acceptance Model (TAM). TAM was extended and some hypotheses were constructed in order to test for users' acceptance of social networks marketing. The paper is

${ }^{1}$ The government-owned telecommunication service provider. 
arranged as follows: Section 2 discusses TAM, Section 3 discusses the methodology used in this work, Section 4 discusses the results and discussions, Section 5 discusses the moderating effect of demographics on TAM, Section 6 presents the conclusions of the study, and Section 7 presents its limitations.

\section{TECHNOLOGY ACCEPTANCE MODEL (TAM)}

\subsection{Background}

According to the Theory of Reasoned Action (TRA) model [7, an individual's performance is determined by his or her behavioural intentions, which are jointly determined by the individual attitudes and subjective norms. Davis [8] defines "attitude towards using a system as the degree of evaluative affect that an individual associates with using the target system in his or her job". TRA is an extended model of Theory of Planned Behaviour (TPB), TRB was derived by including perceived behavioural control as a determinant of behaviour 9. TRA and TPB models are generally used for predicting individual behaviour using construct, such as belief, attitude, intention, and behaviour relationship. Building upon TRA, Davis 10 proposed the Technology Acceptance Model (TAM) to predict user's adoption of information systems. TAM hypothesizes that user adoption of a new information system is determined by the users' intention to use the system, which in turn is determined by the user beliefs about the system. The original TAM is constructed from external variables, Perceived Usefulness (PU) and Perceived Ease of Use (PEOU), attitude towards using Behavioural Intention (BI) and actual usage. The original idea of the theory is that PU and PEOU directly influence the users' intention to use Information Technology (IT). The description of the original TAM by Davis [10] is shown in Fig. 1.

The model explains the reasons why users either accept or reject an Information Technology (IT) or Information System (IS). PU and PEOU are both significant in determining user's intention and can influence user's attitude towards using an IS. The original TAM was later modified by Davis and Venkatesh [11. Davis and Venkatesh removed attitude from the model; the TAM model demonstrated that intention to use is only partly mediated by attitude. The construct of the model involved external variables (external stimulus), PU and PEOU (cognitive response), behavioural intention to use (intention), and actual system use (behaviour).

Davis 10 defined perceived usefulness as the degree to which a person believes that using a particular system would enhance his or her job performance. In addition, he defined perceived ease of use as the degree to which a person believes that using a particular system would be free from physical and mental efforts.

Davis' studies suggested that PEOU is hypothesized to be a major predictor of PU, which has a positive indirect effect on computer self-efficacy through
PU. Observed studies on TAM have shown that the usage of information system is determined by user's behavioural intentions, which are jointly determined by user PU and attitudes toward using the system. Attitude towards using the system is also determined by $\mathrm{PU}$ and PEOU. PU and PEOU both have positive indirect effects on attitude.

TAM framework has been practically used in a wide range of IT researches, such as Internet banking (Suh and Han 12; Wang et al. 13; Eriksson et al. [14]; Lassar et al. [15]), e-shopping [9], and Internet utilization behaviour 16 .

\subsection{Technology Acceptance Model in other context}

There are many similarities in users' intention and their attitude towards adopting e-Commerce activities including social networks marketing. Eastin [17] studied four different e-Commerce activities namely eshopping, banking, investing and online service. Their result showed that self-efficacy, Internet use, PEOU, perceived economic advantage, and adoption of similar innovation have positive influence on users' adoption of any kind of e-Commerce. Eastin suggested that since perceived risk has a negative impact; it should also be considered as a barrier to adoption of any form of e-Commerce.

Yi and Hwang [18] studied TAM using self-efficacy, enjoyment and learning goal orientation as an additional construct to their model. The study showed that self-efficacy has a direct influence on the use of a system, while enjoyment and learning goal orientation mediated through self-efficacy, PU and PEOU. PU and PEOU, in turn, influenced the decision to accept through behavioural intention. An extended TAM was done by Igbaria and Iivari [19] about the effect of self-efficacy on computer usage. Igbaria and Iivari's extended TAM shows that self-efficacy, computer experience, and organizational support were confirmed to have positive direct effect on PEOU. They claimed that PEOU is a crucial factor in determining the acceptability of a particular system.

Quite a lot of research has been done on user acceptance of Internet banking using TAM. Another study on the use of both TRA and TAM showed that previous computer experience, previous technology experience, individual banking experience, reference group, and computer behaviour strongly affect user attitudes and behavioural intentions towards the use of online banking [20]. The study done by Lassar et al. 15] on user acceptance of Internet banking, which used TAM as a framework, showed that the intensity of Internet usage has a significant effect on user acceptance of Internet banking. They concluded that the more skills consumers have in using both computers and the Internet, the easier it is for them to accept the use of Internet banking.

Suh and Han 12; Wang et al. 13] and Eriksson et al. 14 included trust to their TAM constructs. They ascertained trust to be a strong significant factor 


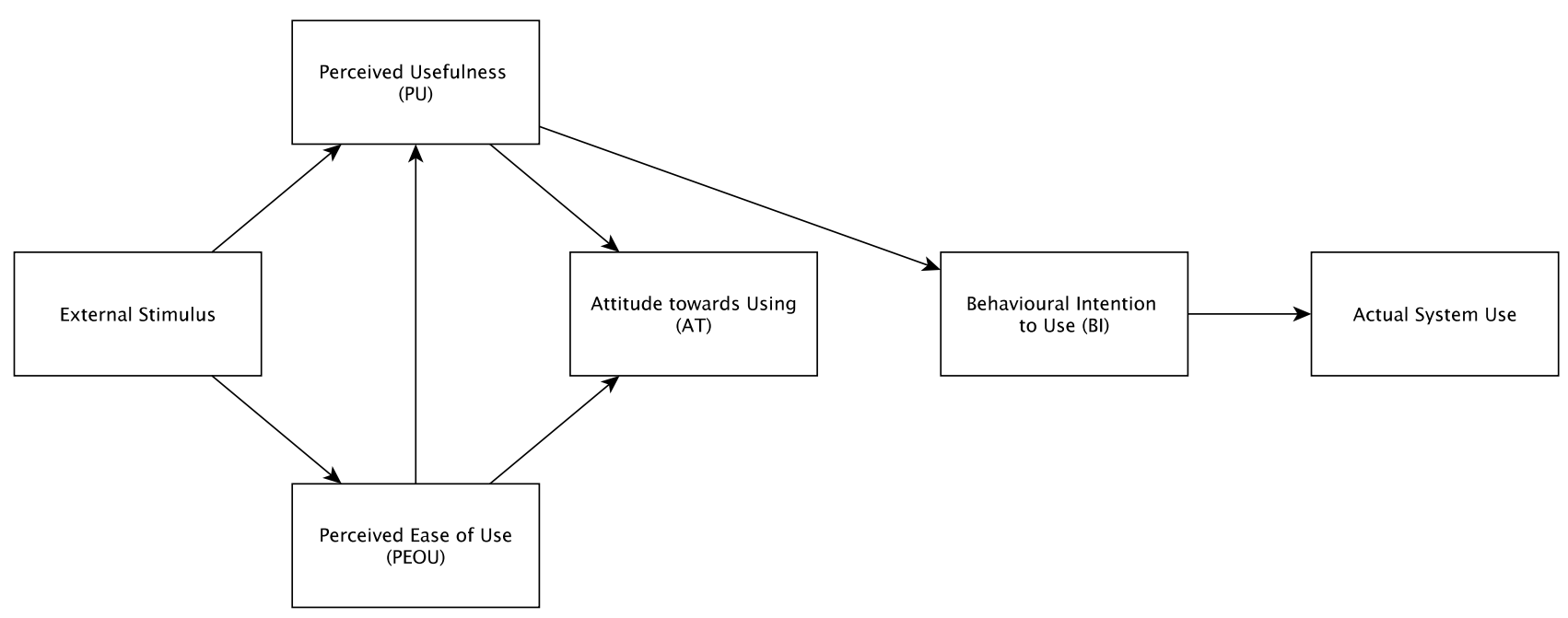

$\begin{array}{lll}\text { External Stimulus } & \text { Cognitive Response } & \text { Bntention }\end{array}$

Figure 1: Original Technology Acceptance Model [10]

in predicting the intention to use Internet banking. Wang et al. 13. also added perceived credibility as a new factor to TAM constructs, and attitude construct was also merged with behavioural intention. Wang et al. confirmed PEOU and PC as the most significant constructs in determining behavioural intention to use Internet banking.

\subsection{Extended TAM and hypotheses}

Considering the uniqueness and simplicity of the Technology Acceptance Model (TAM), this study used extended TAM as a theoretical framework to examine the effects of Computer Self Efficacy (CSE) on user's acceptance of social networks marketing system through four constructs, namely (1) Perceived usefulness (PU), (2) Perceived ease of use (PEOU), (3) Perceived credibility (PC) and (4) Awareness (AWN).

The extended TAM for this study is developed based on the findings derived from the literature reviews. The constructs has been successfully used in different information system contexts; hence, it was adopted for this study.

The proposed research model shown in Fig. 2 includes one variable (computer self-efficacy) and four belief variables (PEOU, PU, PC, and awareness). The selections are supported by previous studies in the information systems literature. Behavioural intention in using a system is determined by $\mathrm{PU}$ and PEOU. On one hand, PEOU has a casual effect on PU. On the other hand, CSE has a direct influence on PU and $\mathrm{PEOU}$ and an indirect influence on PC, AWN and BI [8].

\section{METHODOLOGY}

\subsection{Sampling and procedure}

An Internet survey link was sent to a random sample of students from three tertiary institutions within the Western Cape Province of South Africa (University of Cape Town, Stellenbosch University, and University of Western Cape). The questionnaire was posted to an online community web page and it has a direct link to the online survey site. The students were also requested to forward the URL of the survey to their friends in order to participate in the survey. Some printed copies of the questionnaire were also distributed to other South African indigenes who were users of social network sites. The first part of the questionnaire captured demographic information, and the second part contained 5 point Likert scales (ranging from strongly agree (5) to strongly disagree (1)).

A total of four hundred and seventy (470) responses were captured, with respondents of mixed gender, different ethnicity, cultural, and educational background. From the returned questionnaire only 286 (60\% response rate) were useful. The questionnaire was designed using standard software to ensure an easy-toaccess and easy-to-navigate survey. The survey was kept online for four weeks so as to ensure that less frequent Internet users also participate. Hypothesis questions are shown in Table 1 .

\section{RESULTS AND DISCUSSION}

The analysis was performed with a system designed for statistical analyses (SPSS). The descriptive statistics presented shows an overview of the current use of social networks marketing among the consumers. The degree to which the respondents perceive ease of use and usefulness of SNM were compared with demographical 


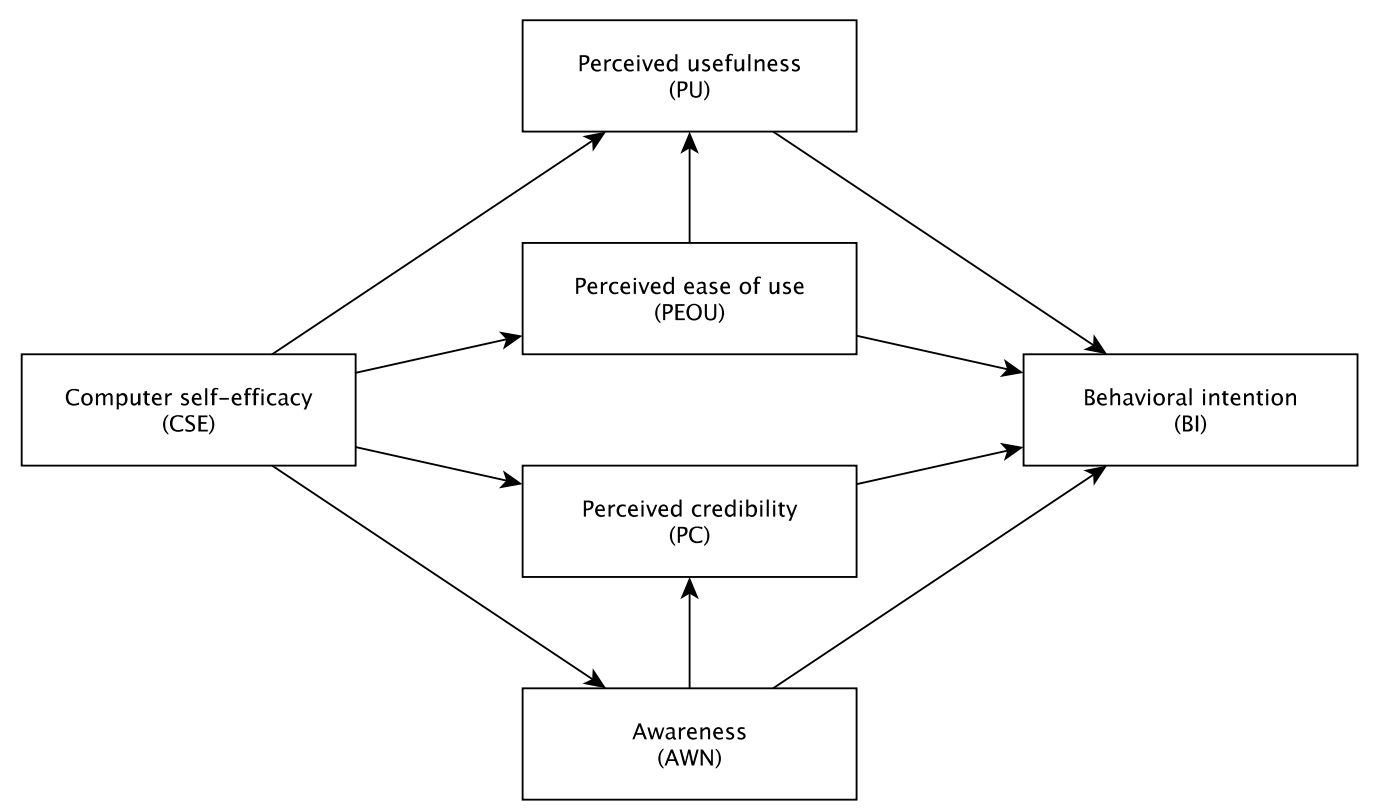

Figure 2: Extended TAM to predict SNM behaviour

questions. Regression analysis was selected as the methods to test for hypotheses. Linear regression was used to determine the correlation and the relationship between the variables.

Table 2 shows the distribution of gender ratio of the respondents of the research. The majority of the respondents $(62.9 \%)$ were male, while $37.1 \%$ were female respondents. The most populous age group category was the '20-29 years' category, with about $58 \%$ of the respondents, and the smallest is the 'above 40 years' category, which has a percentage of $4.2 \%$. Most of the respondents were students (SD), and most of the responses (almost 63\%) came from non-users of SNM systems. Only $22 \%$ were users of the SNM system. Respondents who did not currently useSNM systems but intended to use in future were approximately $15 \%$. The educational background, ethnicity and social networks marketing use are presented in Table 3

In order to give an account of the extent of the use of the system, the degree of PEOU and PU were both compared with different demographic groups. More than three quarters $\left(\frac{3}{4}\right)$ of the whole respondents (consumers) perceived SNM to be easy to use, and about one quarter $\left(\frac{1}{4}\right)$ of the remaining respondents consider it either too hard for them to use or were undecided about the question.

This study tests for the following hypotheses based on the theoretical and empirical support from literature.

H1. Computer self-efficacy will have a positive effect on PU of SNM.

H2. Computer self-efficacy will have a positive effect on PEOU of SNM.

H3. Computer self-efficacy will have a positive effect on PC of SNM.

H4. Computer self-efficacy will have a positive effect on awareness of SNM.

H5. PU will have a positive effect on behavioural intention to use SNM.

H6. PEOU will have a positive effect on perceived usefulness of SNM.

H7. PEOU will have positive effect on behavioural intention to use SNM.

H8. Perceived credibility (PC) will have a positive effect on behavioural intention to use social networks marketing system.

H9. Awareness will have positive effect on perceived credibility of SNM.

H10. Awareness will have positive effect on behavioural intention to use SNM system.

Two-thirds $\left(\frac{2}{3}\right)$ of the whole respondents perceived SNM to be useful or relatively useful for their business transactions. One-third $\left(\frac{1}{3}\right)$ of the remaining respondents either considered SNM not useful to them or were undecided about the question. The cross-tabulations of both PEOU and PU against gender, age and education are presented in Tables 3 and 4 .

\section{MODERATING EFFECT OF DEMOGRAPH- ICS ON TAM}

Moderating effects of demography (gender, age, and education) were tested with all the relationships in the research model. They were found having direct significant effects on behavioural intention to use social networks marketing. The summary of the moderating effects of demographics on the extended TAM is presented in Table 5. The table displays demographics variable that was found to be the strongest moderator (the significant relationship are marked by X sign).

Gender was found moderating four relationships, between PU \& BI, PEOU \& BI, PC \& BI, and AWN $\&$ BI. Age and education were found moderating three relationships. Age has a moderating effect on PU \& BI, PEOU \& PU, and PC \& BI. Education was found to have a moderating effect relationship between PEOU \& 
Table 1: Questions for measuring hypotheses

\begin{tabular}{|c|c|c|c|}
\hline Computer self-efficacy & $\begin{array}{l}\mathrm{H} 1, \mathrm{H} 2, \\
\mathrm{H} 3, \mathrm{H} 4\end{array}$ & 4 & $\begin{array}{l}\text { I can use Internet marketing, including social networks market- } \\
\text { ing... } \\
1 . \ldots \text { if I had access to computer system. } \\
2 . \ldots \text { if I had access to Internet. } \\
3 . \ldots \text { if I had seen someone else using it before. } \\
4 . \ldots \text { if I could get someone to help if I got stuck. }\end{array}$ \\
\hline Perceived usefulness & H5 & 4 & $\begin{array}{l}\text { 1. Using SNM would help me to transact business globally. } \\
\text { 2. Using SNM would help me to communicate and get feedback } \\
\text { from business owners. } \\
\text { 3. Using SNM would reduce time wasting and cost of going to } \\
\text { stores. } \\
\text { 4. I can use SNM, if I found products to buy on the site. } \\
\text { 5. Using SNM would connect me to other customers. }\end{array}$ \\
\hline Perceived ease of use & $\mathrm{H} 6, \mathrm{H} 7$ & 5 & $\begin{array}{l}\text { 1. My interaction with SNM is clear and understandable. } \\
\text { 2. Learning to use SNM would be easy for me. } \\
\text { 3. I would find SNM flexible to interact with. } \\
\text { 4. I would find it easy to use SNM to accomplish all my tasks. } \\
\text { 5. Overall, I would find the proposed system easy to use. }\end{array}$ \\
\hline Perceived credibility & $\mathrm{H} 8$ & 3 & $\begin{array}{l}\text { 1. Using SNM would not disclose my personal information. } \\
\text { 2. I would find SNM secure in conducting my business transac- } \\
\text { tions. } \\
\text { 3. I can use SNM, if I have trust in companies marketing on } \\
\text { the site }\end{array}$ \\
\hline Awareness & $\begin{array}{l}\text { H9, } \\
\text { H10 }\end{array}$ & 3 & $\begin{array}{l}\text { 1. I can use SNM, if business owners can create more awareness } \\
\text { on the site. } \\
\text { 2. I can use SNM, if I see the advert on my wall profile. } \\
\text { 3. I would found SNM more valuable if a friend tells me about } \\
\text { it. }\end{array}$ \\
\hline
\end{tabular}

PU, PEOU \& BI, and PC \& BI. Of all the moderators, gender was found to be the strongest, moderating all the relationships except PEOU. Each of the hypotheses tested in this study and their statistical significance in the use of SNM systems are tested and summarized in Table 6 .

\subsection{Analysis of the hypotheses testing}

Hypotheses $\mathrm{H} 1$ and $\mathrm{H} 2$ are based on the assumption that the more access users have to both computer system and Internet services, the more likely they will find the proposed system useful and easy to use (see Table 1). The results show that $\mathrm{H} 1$ and $\mathrm{H} 2$ are supported, thereby confirming a positive significant relationship. The third hypothesis (H3) is based on the assumption that the more confidently users access both computer system and Internet services, the more likely they will find the proposed system credible and secure to use. The assumption here is not supported: H3 shows a negative statistical significant relationship and corre- lation between computer self-efficacy and perceived credibility. The fourth hypothesis (H4) is based on the assumption that the more users get access to both computer system and Internet services, the more they will frequently consider the awareness of the newly proposed system. Regression analysis and Pearson correlation analysis was conducted in order to observe the relationships in details. The results show that H4 is supported, thereby confirming a positive significant relationship and correlation between computer self-efficacy and awareness. The results obtained supported $\mathrm{H} 5$, thereby confirming a positive significant relationship and correlation between PU and user's intention. For any application perceived to be easy to use, it is more likely that user's will find it useful. In addition, it will definitely increase users' intention to accept and use such a system. Tests of H6 and H7 show a positive statistically significant relationship. The usage intention of accepting a system could also be affected by users' perceptions on credibility with respect totrust, security and privacy. Any system found 
Table 2: Demographics of respondents

\begin{tabular}{|c|c|c|c|c|c|}
\hline & & & Percent & Valid & Cumulative \\
\hline Gender & $\begin{array}{l}\text { Male } \\
\text { Female }\end{array}$ & $\begin{array}{l}180 \\
106\end{array}$ & $\begin{array}{l}62.9 \\
37.1\end{array}$ & $\begin{array}{l}62.9 \\
37.1\end{array}$ & $\begin{array}{l}62.9 \\
100.0\end{array}$ \\
\hline Age & $\begin{array}{l}<20 \text { years } \\
20-29 \text { years } \\
30-39 \text { years } \\
40-49 \text { years } \\
\text { Total }\end{array}$ & $\begin{array}{l}50 \\
166 \\
52 \\
18 \\
286\end{array}$ & $\begin{array}{l}17.5 \\
58.0 \\
18.2 \\
6.3 \\
100.0\end{array}$ & $\begin{array}{l}17.5 \\
58.0 \\
18.2 \\
6.3 \\
100.0\end{array}$ & $\begin{array}{l}17.5 \\
75.5 \\
93.7 \\
100\end{array}$ \\
\hline Educational & $\begin{array}{l}\text { Undergraduate } \\
\text { University gradu- } \\
\text { ate } \\
\text { Masters } \\
\text { PhD } \\
\text { Total } \\
\end{array}$ & $\begin{array}{l}160 \\
60 \\
54 \\
12 \\
286 \\
\end{array}$ & $\begin{array}{l}55.9 \\
21.0 \\
18.9 \\
4.2 \\
100.0 \\
\end{array}$ & $\begin{array}{l}55.9 \\
21.0 \\
18.9 \\
4.2 \\
100.0 \\
\end{array}$ & $\begin{array}{l}55.9 \\
76.9 \\
95.8 \\
100.0\end{array}$ \\
\hline Status & $\begin{array}{l}\text { Student } \\
\text { Member of busi- } \\
\text { ness org. } \\
\text { Member of govern- } \\
\text { ment org. } \\
\text { Member of organi- } \\
\text { zational setup } \\
\text { Total }\end{array}$ & $\begin{array}{l}224 \\
36 \\
8 \\
18 \\
286\end{array}$ & $\begin{array}{l}78.3 \\
12.6 \\
2.8 \\
6.3 \\
100.0\end{array}$ & $\begin{array}{l}78.3 \\
12.6 \\
2.8 \\
6.3 \\
100.0\end{array}$ & $\begin{array}{l}78.3 \\
90.9 \\
93.7 \\
100.0\end{array}$ \\
\hline Ethnicity & $\begin{array}{l}\text { White } \\
\text { Black } \\
\text { Coloured } \\
\text { Indian } \\
\text { Total }\end{array}$ & $\begin{array}{l}98 \\
138 \\
46 \\
4 \\
286\end{array}$ & $\begin{array}{l}34.3 \\
48.3 \\
16.1 \\
1.4 \\
100.0\end{array}$ & $\begin{array}{l}34.3 \\
48.3 \\
16.1 \\
1.4 \\
100.0\end{array}$ & $\begin{array}{l}34.3 \\
82.5 \\
98.6 \\
100.0\end{array}$ \\
\hline SNM use & $\begin{array}{l}\text { Use } \\
\text { Don't use } \\
\text { Use in future } \\
\text { Total }\end{array}$ & $\begin{array}{l}62 \\
180 \\
44 \\
286\end{array}$ & $\begin{array}{l}21.7 \\
62.9 \\
15.4 \\
100.0\end{array}$ & $\begin{array}{l}21.7 \\
62.9 \\
15.4 \\
100.0\end{array}$ & $\begin{array}{l}21.7 \\
84.6 \\
100.0\end{array}$ \\
\hline
\end{tabular}

to be credible enough is most likely to increase users' intention to use such a system. Test of H8 confirms a positive statistically significant relationship between perceived credibility and behavioural intention.

H9 states that Awareness will have positive effect on perceived credibility of social networks marketing. The empirical results of this hypothesis do not support the assumption. Although, there was a moderate statistically significant relationship and correlation between awareness and perceived credibility, the direction of the relationship indicates a negative relationship. The results indicate that even if there is persistent awareness on SNM, users will still find the system not credible enough to use. H10 is similar to H9, and states that awareness will have positive effect on behavioural intention to use social networks marketing. Based on the rules for measuring the strength of a relationship, H10 indicates a positive statistically significant relationship between awareness and behavioural intention. The standardized regression of the extended TAM is shown in Fig. 3. The result showed the direction and the relationship of all the hypotheses used in the extended TAM, along with the R-squared result.

The extended TAM involved 10 hypotheses, which were used to determine if the use of the SNM system is statistically significant or not. The result presented in Table 6 shows that 8 out of the 10 hypotheses were found statistically significant and two were statistically insignificant. Only hypotheses 3 and 9 were rejected. That is, they did not conform to the original hypothesis suggested for this study due to their weak and negative relationships, while others were supported. The results suggest that both Hypotheses 3 and 9 are statistically insignificant. All other hypotheses were found to be statistically significant since the results met the original hypothesis suggested for this study.

The empirical results observed from this study show that computer self-efficacy has positive significant effects on behavioural intention to use SNM through perceived usefulness, perceived ease of use and awareness. Only perceived credibility was found to have a negative effect through computer self-efficacy. However, both computer self-efficacy and awareness have negative significant effects on perceived credibility. The observation is similar to Eastin's observation [17] that perceived risk should be considered as a barrier to any form of e-Commerce adoption. The extended TAM shows that computer self-efficacy strongly influence PU and PEOU. The influence shows that the more users have skills in using both computer and the Internet, the more likely for them to find the SNM system useful and easy to use. This finding is supported by previous research that the more experience consumers have in using computers and the Internet, the more likely for 
Table 3: Cross-tabulations of PEOU to gender, age and education

\begin{tabular}{|l|l|l|l|l|}
\hline & & $\begin{array}{l}\text { Easy to use } \\
(\%)\end{array}$ & $\begin{array}{l}\text { Undecided } \\
(\%)\end{array}$ & $\begin{array}{l}\text { Hard to use } \\
(\%)\end{array}$ \\
\hline Gender & Male & 77.8 & 17.8 & 4.4 \\
& Female & 84.9 & 13.2 & 1.9 \\
\hline Age & $<20$ years & 88 & 12 & 0 \\
& $20-29$ years & 73.5 & 21.7 & 4.8 \\
& 30-39 years & 88.5 & 7.7 & 3.8 \\
& 40 and above & 100 & 0 & 0 \\
\hline Education & Undergraduate & 78.8 & 17.5 & 3.8 \\
& University graduate & 80.0 & 13.3 & 6.7 \\
& Masters & 81.5 & 18.5 & 0 \\
& PhD & 100 & 0 & 0 \\
\hline
\end{tabular}

Table 4: Cross-tabulations of PU to gender, age and education

\begin{tabular}{|l|l|l|l|l|}
\hline & & Useful $(\%)$ & $\begin{array}{l}\text { Undecided } \\
(\%)\end{array}$ & $\begin{array}{l}\text { Not useful } \\
(\%)\end{array}$ \\
\hline Gender & Male & 70 & 18.9 & 11.1 \\
& Female & 73.6 & 24.5 & 1.9 \\
\hline Age & $<20$ years & 76 & 8 & 16 \\
& 20-29 years & 63.9 & 28.9 & 7.2 \\
& 30-39 years & 80.8 & 15.4 & 3.8 \\
& 40 and above & 100 & 0 & 0 \\
\hline Education & Undergraduate & 68.8 & 22.5 & 8.8 \\
& University graduate & 76.7 & 13.3 & 10 \\
& Masters & 70.4 & 25.9 & 3.7 \\
& PhD & 83.3 & 16.7 & 0 \\
\hline
\end{tabular}

they will use Internet banking [15]. Studies by Igbaria and Iivari [19] and Davis and Venkatesh [1] found a significant relationship between computer self-efficacy, PU and PEOU.

This study also found that PEOU strongly influence PU, which is supported by most of the TAM studies found in the literature. PEOU is often hypothesized to have a direct significant effect on PU [21] [10]. Hence, the extended TAM suggests that the more users perceived SNM system to be easier to use, the more likely they perceived the system to be useful. Both PC and $\mathrm{PU}$ have the strongest influence on behavioural intension to use SNM.

Finally, the results from this study also found one of the new TAM constructs perceived credibility and one of the old construct (perceived usefulness) to have the strongest influence in predicting user's intention to use SNM. This result is supported by Wang et al. [13, which discovered that PC and PEOU have the strongest significant effects on behavioural intention to use Internet banking than PU. Pikkarainen et al. 22 also identified PU and awareness as the two major constructs affecting the use of online banking.

\section{CONCLUSIONS}

This study has successfully used TAM to investigate the level of acceptance of social networks marketing system within the Western Cape province of South Africa, a place that has recently become popular in Internet marketing. Using the TAM theoretical framework, this study has added two new constructs, 'Perceived Credibility' and 'Awareness', as part of the factors affecting user acceptance of social networks marketing. In addition, this study presented the extent of usage of SNM by the consumers. Lastly, the degree of SNM usage was compared among different demographic groups based on gender, age group and education.

The extended TAM used in this study involved ten hypotheses, which were used to determine if the use of the SNM system is statistically significant or not. Each of the hypotheses was tested and the findings show that eight out of the ten hypotheses were statistically significant with the hypotheses suggested, and two of the hypotheses (H3 and H9) were statistically insignificant.

As hypothesized, the significant effects of $\mathrm{PU}$, PEOU, PC and Awareness on behavioural intention to use SNM were all statistically significant. There is a growing distrust in the field about the ability to recognize the actual measure that strongly determines user acceptance. In addition, the observation in this research showed that both 'Perceived Credibility' and 'Perceived Usefulness' have the greater influence on user's intention to use SNM. In comparison to other studies that have successfully used 'Perceived Credibility' as part of their extended TAM construct, this study successfully exploited 'Perceived Credibility' and 'Awareness' as part of the constructs that determine users acceptance of SNM. Like many other studies that 
Table 5: Summary of the moderators of the extended TAM

\begin{tabular}{|l|l|l|l|l|l|}
\hline Moderating variable & PU \& BI & PEOU \& PU & PEOU \& BI & PC \& BI & AWN \\
\hline Gender & $\mathrm{X}$ & $\mathrm{X}$ & $\mathrm{X}$ & $\mathrm{X}$ \\
Age & $\mathrm{X}$ & $\mathrm{X}$ & $\mathrm{X}$ & $\mathrm{X}$ & \\
Education & & $\mathrm{X}$ & $\mathrm{X}$ & \\
\hline
\end{tabular}

Table 6: Hypotheses' statistical significance

\begin{tabular}{|l|l|l|l|l|l|l|l|}
\hline Hypothesis & $\begin{array}{l}\text { Regression } \\
\text { and Pear- } \\
\text { son cor- } \\
\text { relation } \\
\text { analysis }\end{array}$ & & R square & $\begin{array}{l}\text { Adjusted R } \\
\text { square }\end{array}$ & $\begin{array}{l}\text { Std. error } \\
\text { of the esti- } \\
\text { mate }\end{array}$ & $\begin{array}{l}\text { R square } \\
\text { change }\end{array}$ & $\begin{array}{l}\text { Sig. } \\
\text { change }\end{array}$ \\
\hline H1 & Supported & 0.941 & 0.914 & 0.913 & 0.742 & 0.914 & 0.156 \\
H2 & Supported & 0.939 & 0.905 & 0.904 & 0.588 & 0.905 & 0.130 \\
H3 & Rejected & -0.340 & -0.283 & -0.282 & 3.070 & -0.283 & 0.053 \\
H4 & Supported & 0.899 & 0.808 & 0.807 & 1.369 & 0.808 & 0.095 \\
H5 & Supported & 0.946 & 0.894 & 0.893 & 1.599 & 0.894 & 0.145 \\
H6 & Supported & 0.976 & 0.959 & 0.958 & 0.962 & 0.959 & 0.336 \\
H7 & Supported & 0.942 & 0.887 & 0.886 & 1.594 & 0.887 & 0.132 \\
H8 & Supported & 0.953 & 0.909 & 0.908 & 0.965 & 0.909 & 0.172 \\
H9 & Rejected & -0.707 & 0.697 & 0.696 & 2.085 & -0.697 & 0.013 \\
H10 & Supported & 0.943 & 0.889 & 0.888 & 0.919 & 0.889 & 0.164 \\
\hline
\end{tabular}

used TAM, PEOU was also found to strongly influence PU.

Furthermore, the findings showed that the younger respondents (most active users of SNM) make use of SNM as a powerful marketing tool, which can be explored by many small and medium-sized enterprises in South Africa. In order to ensure optimum use of this new medium of marketing by the consumers, it is important that factors, such as security, credibility and awareness are taken into consideration by SMEs in South Africa. This study suggests that secured Internet access will increase consumer perceptions of ease of use and usefulness of SNM. Lastly, high credibility of Internet system will support consumer willingness to use online social networks marketing in South Africa.

\section{LIMITATIONS}

The investigation of social networks marketing acceptance in South Africa is relatively new in IS research. Hence, the impact of findings in this empirical study might not be significant enough to contribute to the body of knowledge. The findings were obtained from one single study and the sample size used for the study was too small to explain regression results. Hence, caution needs to be exercised, when comparing the findings with that of bigger samples. In addition, the result should be carefully generalized, when predicting SNM behaviour of both experienced and inexperienced SNM users. The reason is that the findings from this study showed that the percentage of respondents experience in SNM is low. This may affect the extent of PU and PEOU of SNM between experienced respondents and inexperienced respondents. Linear regression, rather than the structural equation model, was used to test for the relationship among the constructs used in the extended TAM. Another limitation is that the use of SNM measures was self-reported. The reason is that it is a bit complex to determine how accurately self-reports reflect actual usage of a proposed system.

\section{REFERENCES}

[1] J. Kevin. "Social networking: Changing the way we communicate and do business". International School of Management MPRA Paper No. 18502, 2009.

[2] D. Boyd and N. Ellison. "Social network sites: Definition, history, and scholarship". Journal of computermediated communication, vol. 13, no. 1, 2007.

[3] R. Zheng, D. Wilkinson and F. Provost. "Social network collaborative filtering", 2008. Working paper.

[4] O. Palemo. "Is social media marketing relevant for the Nigerian business environment". 2008. URL http://www.incorporatenigeria com/magazine/conversion-report/64-is-socialmedia-marketing-relevant-for-the-nigerianenvironment

[5] K. Chipp and Z. Ismail. E-Commerce a southern African perspective: The e-Commerce environment. Claremont, South Africa: New Africa Books, 2004.

[6] M. Mulero and M. Adeyeye. "Usage of social networks marketing by small and medium-scale enterprises in South Africa: A review of some SMEs in Cape Town". In Proceedings of the IST-Africa 2011, Gaborone, Botswana, May 11 - 13, 2011. 2011.

[7] M. Fishbein and I. Ajzen. Belief, attitude, intention and behavior: An introduction to theory and research. Reading, MA: Addison-Wesley, 1975.

[8] F. Davis. "Users' acceptance of information technology: System characteristics, users' perception and behavioural impacts". International journal of manmachine studies, vol. 38, no. 3, pp. 475-487, 1993. 


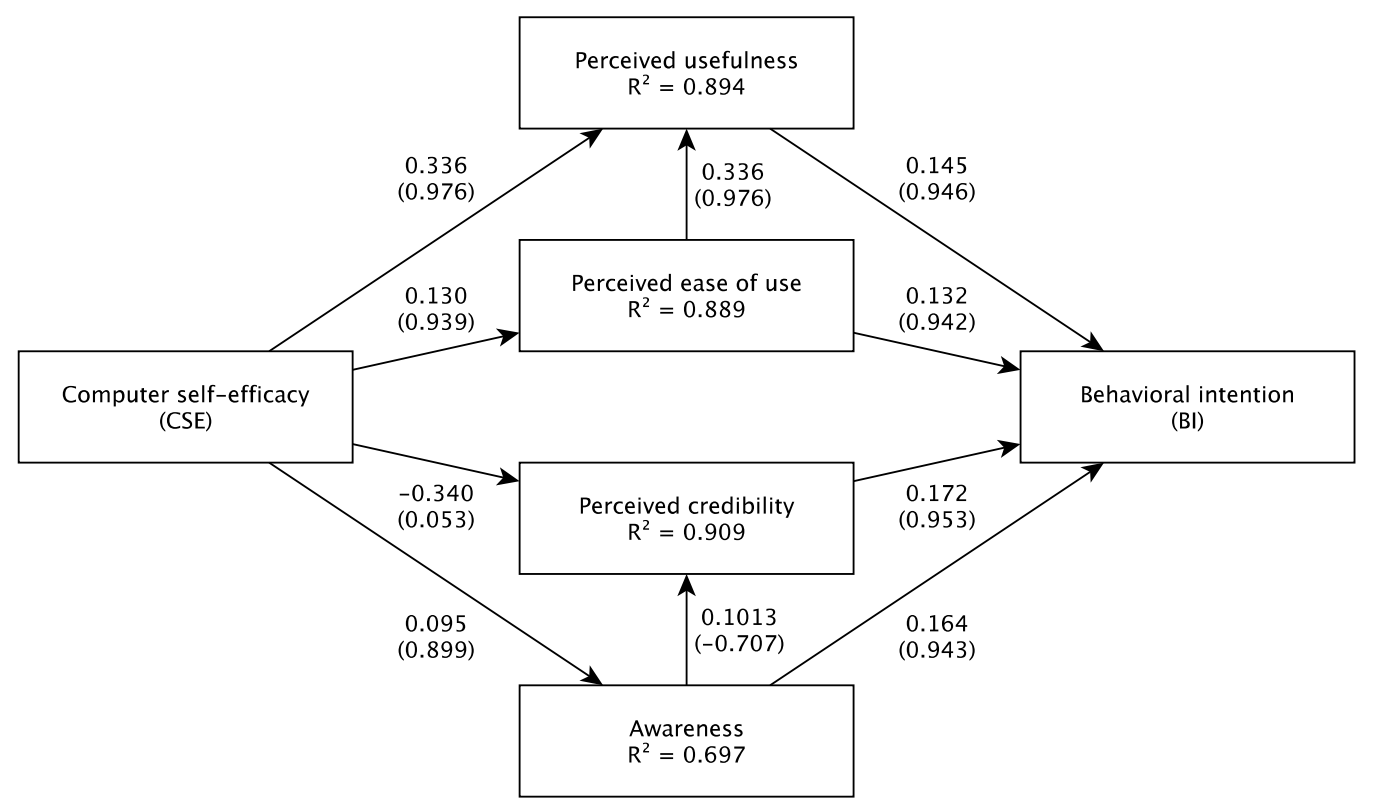

Figure 3: Standardized regression of the extended TAM

[9] H.-P. Shih. "An empirical study on predicting user acceptance of e-shopping on the web". Information and management, vol. 41, no. 6, pp. 351-368, 2004.

[10] F. Davis. "Perceived usefulness, perceived ease of use, and user acceptance of information technology". MIS quarterly, vol. 13, no. 3, pp. 319-340, 1989.

[11] F. Davis and V. Venkatesh. "A critical assessment of potential measurement biases in the technology acceptance model: three experiments". International journal of human computer studies, vol. 45, pp. 19-45, 1996.

[12] B. Suh and I. Han. "Effect of trust on customer acceptance of internet banking". Electronic commerce research and applications, vol. 1, pp. 247-263, 2002.

[13] Y.-S. Wang, Y.-M. Wang, H.-H. Lin and T. Tang. "Determinants of user acceptance of internet banking: An empirical study". International journal of service industry management, vol. 14, no. 5, pp. 501-519, 2003.

[14] K. Eriksson, K. Kerem and D. Nilsson. "Customer acceptance of internet banking in Estonia". International journal of bank marketing, vol. 23, no. 2, pp. 200-216, 2004.

[15] W. Lassar, C. Manolis and S. Lassar. "The relationship between consumer innovativeness, personal characteristics and online banking adoption". International journal of bank marketing, vol. 23, no. 2, pp. 176-199, 2005.

[16] H.-P. Shih. "Extended technology acceptance model of internet utilization behaviour". Information and management, vol. 41, no. 6, pp. 719-729, 2004.

[17] M. Eastin. "Diffusion of e-Commerce: An analysis of the adoption of four e-Commerce activities". Telematics and informatics, vol. 19, pp. 251-267, 2002.

[18] M. Yi and Y. Hwang. "Predicting the use of web-based information systems: Self-efficacy, enjoyment, learning goal orientation, and the technology acceptance model". International journal of human computer studies, vol. 59, pp. 431-449, 2003.
[19] M. Igbaria and J. Iivari. "The effects of self-efficacy on computer usage". Omega: The international journal of management science, vol. 23, no. 6, pp. 587-605, 1995.

[20] H. Karjaluoto, M. Mattila and T. Pento. "Factors underlying attitude formation towards online banking in Finland". International journal of bank marketing, vol. 20, no. 6, pp. 261-272, 2002.

[21] R. Raitoharju. Information Technology Acceptance in the Finnish Social and Healthcare Sector B Exploring the Effects of Cultural Factors. Turun kauppakorkeakoulun julkaisuja. Turku: Turku School of Economics, 2007.

[22] T. Pikkarainen, K. Pikkarainen, H. Karjaluoto and S. Pahnila. "Consumer acceptance of online banking: an extension of the technology acceptance model". Internet research, vol. 14, no. 3, pp. 224-235, 2004. 